\title{
Radiofrequency ablation versus resection for Barcelona clinic liver cancer very early/early stage hepatocellular carcinoma: a systematic review
}

REVIEW

This article was published in the following Dove Press journal:

Therapeutics and Clinical Risk Management

23 February 2016

Number of times this article has been viewed

\author{
Zhen-Xin $\mathrm{He}^{\prime}$ \\ Pu Xiang ${ }^{2}$ \\ Jian-Ping Gong' \\ Nan-Sheng Cheng ${ }^{3}$ \\ Wei Zhang ${ }^{4}$ \\ 'Department of Hepatobiliary Surgery, \\ the Second Affiliated Hospital, \\ Chongqing Medical University, \\ Chongqing, ${ }^{2}$ State Key Laboratory \\ of Biotherapy and Cancer Center, \\ ${ }^{3}$ Department of Bile Duct Surgery, \\ West China Hospital, Sichuan \\ University, Chengdu, ${ }^{4}$ Department \\ of Hepatobiliary Surgery, Yue Bei \\ People's Hospital, Shaoguan, \\ Guangdong, People's Republic \\ of China
}

Correspondence: Wei Zhang Department of Hepatobiliary Surgery, Yue Bei People's Hospital, Shaoguan, Guangdong 5 12000, People's Republic of China

Tel +86 I8922584247

Email 406518395@qq.com
Aim: To compare the long-term survival outcomes of radiofrequency ablation and liver resection for single very early/early stage hepatocellular carcinoma (HCC).

Methods: The Cochrane Library (Issue 3, 2015), Embase (1974 to March 15, 2015), PubMed (1950 to March 15, 2015), Web of Science (1900 to March 15, 2015), and Chinese Biomedical Literature Database (1978 to March 15, 2015) were searched to identify relevant trials. Only trials that compared radiofrequency ablation and liver resection for single very early stage $(\leq 2 \mathrm{~cm})$ or early stage $(\leq 3 \mathrm{~cm}) \mathrm{HCC}$ according to the Barcelona clinic liver cancer (BCLC) staging system were considered for inclusion in this review. The primary outcomes that we analyzed were the 3 -year and 5-year overall survival (OS) rates, and the secondary outcomes that we analyzed were the 3-year and 5-year disease-free survival (DFS) rates. Review Manager 5.3 was used to perform a cumulative meta-analysis. Possible publication bias was examined using a funnel plot. A random-effects model was applied to summarize the various outcomes.

Results: Six studies involving 947 patients were identified that compared radiofrequency ablation $(n=528)$ to liver resection $(n=419)$ for single BCLC very early HCC. In these six studies, the rates of 3-year OS, 5-year OS, 3-year DFS, and 5-year DFS were significantly lower in the radiofrequency ablation group than in the liver resection group (risk ratio $[R R]=0.90$, 95\% confidence interval [CI]: $0.83-0.98, P=0.01 ; \mathrm{RR}=0.84,95 \% \mathrm{CI}: 0.75-0.95, P=0.004$; $\mathrm{RR}=0.77,95 \% \mathrm{CI}: 0.60-0.98, P=0.04$; and $\mathrm{RR}=0.70,95 \% \mathrm{CI}: 0.52-0.94, P=0.02$, respectively). Ten studies involving 2,501 patients were identified that compared radiofrequency ablation $(n=1,476)$ to liver resection $(n=1,025)$ for single BCLC early HCC. In these ten studies, the rates of 3-year OS, 5-year OS, 3-year DFS, and 5-year DFS were also significantly lower in the radiofrequency ablation group than in the liver resection group ( $\mathrm{RR}=0.93,95 \% \mathrm{CI}$ : $0.88-0.98$, $P=0.003 ; \mathrm{RR}=0.84,95 \% \mathrm{CI}: 0.75-0.94, P=0.002 ; \mathrm{RR}=0.72,95 \% \mathrm{CI}: 0.58-0.89, P=0.002$; and RR $=0.47,95 \%$ CI: $0.33-0.67, P<0.0001$, respectively).

Conclusion: The long-term survival outcomes for patients with single BCLC very early/early stage HCC appear to be superior after liver resection compared to radiofrequency ablation.

Keywords: radiofrequency ablation, liver resection, hepatocellular carcinoma, systematic review

\section{Introduction}

Hepatocellular carcinoma (HCC) ranks sixth in terms of the most common neoplasms. ${ }^{1-3}$ The age-adjusted overall incidence of HCC was $\sim 16$ cases per 100,000 individuals in 2008. ${ }^{1-3} \mathrm{HCC}$ is highly prevalent in Asia, and its incidence is increasing in Europe and in the US. ${ }^{4}$ In recent decades, the development of diagnostic technology and the widespread screening of populations with a high risk of developing $\mathrm{HCC}$ have increased the detection of early stage HCC..$^{5-7}$ 
Liver transplantation is regarded as the best curative approach for early stage HCC. However, only a small percentage of patients are offered this treatment due to high hospital costs and a shortage of liver donors. ${ }^{5-9}$ Liver resection is also a good surgical treatment for early stage HCC, and the 5-year survival rate of this procedure is $>50 \%$. $^{6-8}$ However, some patients with HCC cannot undergo a liver resection due to either poor liver function or rejection. Many nonsurgical treatments have been proposed for these patients, such as radiofrequency ablation, microwave coagulation, and high-intensity focused ultrasound. ${ }^{10-14}$

The management of very early stage (Child-Pugh A, solitary $\leq 2 \mathrm{~cm}$ ) and early stage (Child-Pugh A or B, solitary $\leq 3 \mathrm{~cm}) \mathrm{HCC}$, according to the Barcelona clinic liver cancer (BCLC) staging system, is controversial. ${ }^{15}$ Various systematic reviews and meta-analyses have confirmed the short-term efficacy of radiofrequency ablation for BCLC early stage $\mathrm{HCC} .{ }^{16}$ The role of radiofrequency ablation in the management of BCLC very early stage HCC has not been systematically evaluated. The long-term survival outcome of patients with HCC is an important measure for the evaluation of various treatments. ${ }^{5-7}$ This systematic review compares the long-term survival outcomes of radiofrequency ablation versus liver resection for patients with single BCLC very early/early stage HCC.

\section{Materials and methods Study selection}

The Cochrane Library (Issue 3, 2015), Embase (1974 to March 15, 2015), PubMed (1950 to March 15, 2015), Web of Science (1900 to March 15, 2015), and Chinese Biomedical Literature Database (1978 to March 15, 2015) were searched to identify trials that compared radiofrequency ablation with liver resection in the management of single BCLC very early/early stage HCC. The following keywords were used in these searches: catheter ablation, radiofrequency ablation, liver resection, hepatectomy, liver cancer, $\mathrm{HCC}$, and liver neoplasm. The references of the relevant publications were also manually searched to identify any additional relevant clinical trials.

\section{Criteria for inclusion and exclusion}

The criteria for inclusion of the identified studies were as follows: 1) conformance to the BCLC staging classification: very early stage (Child-Pugh $A$, solitary $\leq 2 \mathrm{~cm}$ ) or early stage (Child-Pugh A or B, solitary $\leq 3 \mathrm{~cm}$ ); 2) comparison of the effects of radiofrequency ablation versus liver resection for single BCLC very early/early stage HCC, irrespective of etiology or the presence of liver cirrhosis or viral hepatitis; and 3 ) at least one outcome of interest reported.

The criteria for exclusion were as follows: 1) investigation of $\mathrm{HCC}$ nodules of $>3 \mathrm{~cm}$; 2) investigation of recurrent $\mathrm{HCC}$; and 3 ) investigation of patients with cholangiocarcinomas or liver metastases.

\section{Data extraction}

The following data were extracted from each trial by two independent authors: 1) study design; 2) year of publication and authors; 3) number and characteristics of patients; and 4) outcome measures. The discrepancy between the two authors was resolved by discussion.

\section{Outcomes}

The primary outcomes measured in this review were the 3 -year and 5-year overall survival (OS) rates. The secondary outcomes measured in this review were the 3-year and 5-year disease-free survival (DFS) rates.

\section{Quality and publication bias assessment}

The quality of each trial was evaluated using the GRADE system. ${ }^{17}$ Funnel plots were applied to evaluate publication bias. ${ }^{18}$ Both visual asymmetry and Egger's linear regression test were used to examine the existence of publication bias. ${ }^{19}$

\section{Statistical analysis}

Review Manager 5.3 (RevMan; Cochrane Collaboration, Oxford, UK) was used to perform a meta-analysis. Statistical heterogeneity among trials was determined by the chi-square test. ${ }^{20}$ The risk ratio (RR) and 95\% confidence interval (CI) were used to evaluate the treatment efficacy. ${ }^{20} \mathrm{~A}$ result was regarded as statistically significant if the $P$-value was $<0.05 .{ }^{20} \mathrm{~A}$ random-effects model was used to summarize the various outcomes for conservative estimates. We conducted the meta-analysis and systematic review according to the Cochrane Handbook for Systematic Reviews of Interventions and Preferred Reporting Items for Systematic Reviews and Meta-Analyses. ${ }^{21,22}$

\section{Results}

\section{Search results}

A total of 4,830 records were identified by electronic searches of the Cochrane Library $(n=322)$, Embase $(n=1,847)$, PubMed $(n=1,581)$, Web of Science $(n=820)$, and Chinese Biomedical Literature Database $(n=260)$ and a manual search of the reference lists of the included trials $(n=6)$. We excluded 1,200 duplicated records and 3,612 irrelevant records by 
screening titles and abstracts. Twenty-four full-text articles were retrieved for further assessment. We excluded eleven articles for the reasons listed in Figure 1.

\section{Description of studies}

Thirteen studies published between 2008 and 2015 fulfilled the inclusion criteria, including two randomized controlled trials (RCTs) and eleven nonrandomized studies (NRS). ${ }^{23-35}$ Three studies compared radiofrequency ablation with liver resection for BCLC very early stage $\mathrm{HCC},,^{25,29,30}$ seven studies compared radiofrequency ablation with liver resection for BCLC early stage HCC, ${ }^{23,24,31-35}$ and three studies compared radiofrequency ablation with liver resection for both BCLC very early stage and early stage HCC..$^{26-28}$ A total of six studies including 947 patients (528 radiofrequency ablations and 419 liver resections) compared radiofrequency ablation with liver resection for BCLC very early stage HCC..$^{25-30}$ Ten studies with a total of 2,501 patients (1,476 radiofrequency ablations and 1,025 liver resections) compared radiofrequency ablation with liver resection for BCLC early stage HCC..$^{23-25,29-35}$ The characteristics and quality of the included trials are presented in Tables 1 and 2.

\section{Effects of interventions \\ Radiofrequency ablation versus liver resection for single BCLC very early stage HCC}

The outcome measures data are presented in Table 3.

Three-year OS rate: Five studies ${ }^{25-27,29,30}$ reported this outcome. Patients in the radiofrequency ablation group had significantly lower 3-year OS rate than those in the liver resection group $(\mathrm{RR}=0.90,95 \% \mathrm{CI}: 0.83-0.98, P=0.01$; heterogeneity: $I^{2}=54 \%, P=0.07$; Figure $2 \mathrm{~A}$ ).

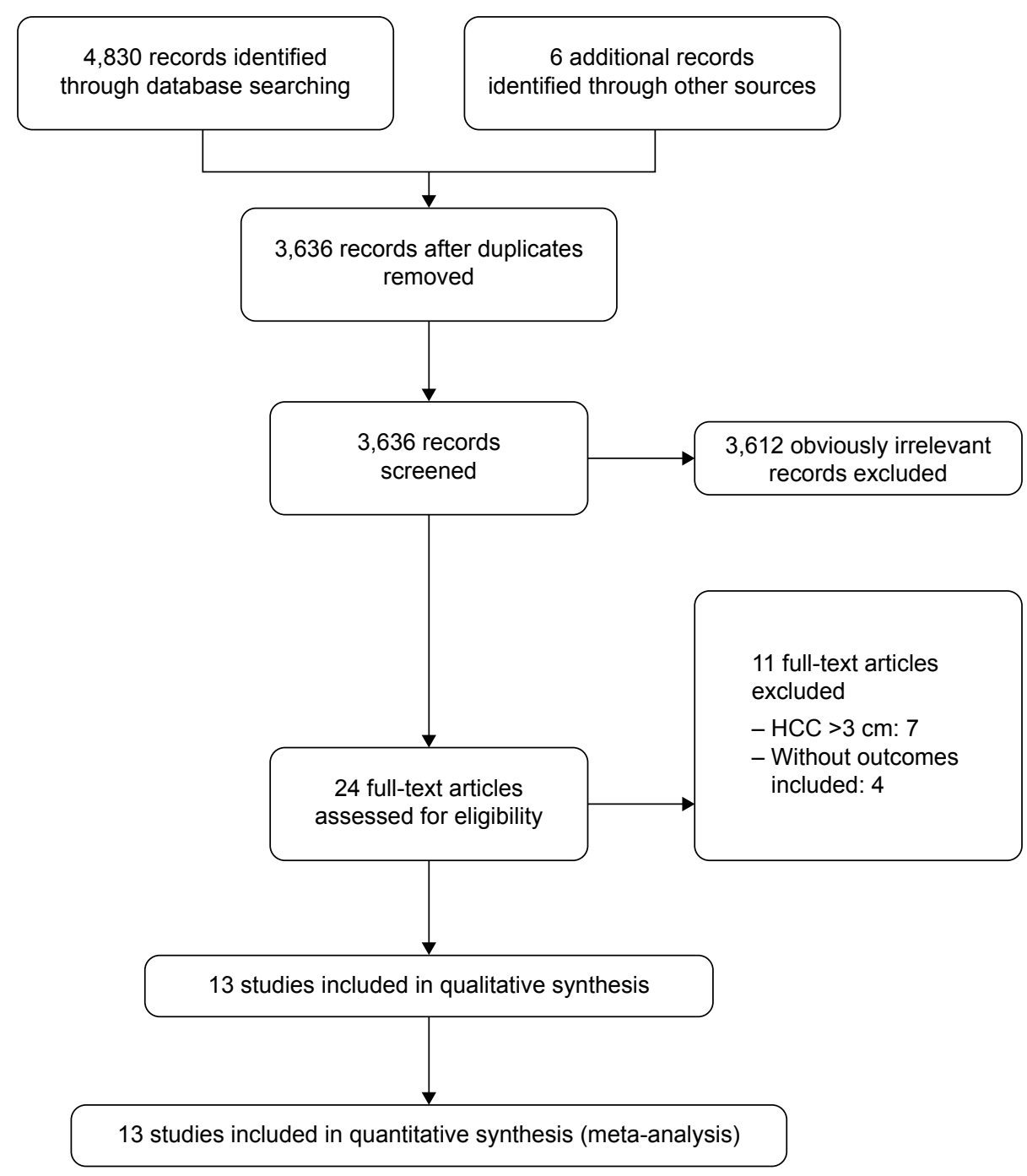

Figure I Flow diagram showing study selection process. Abbreviation: HCC, hepatocellular carcinoma. 
Table I Characteristics and quality of included studies for single BCLC very early stage HCC

\begin{tabular}{|c|c|c|c|c|c|c|}
\hline Author & Year & Country & Design & $\begin{array}{l}\text { Participants } \\
\text { (RFA/LR) }\end{array}$ & $\operatorname{Sex}(M / F)$ & $\begin{array}{l}\text { Quality of the } \\
\text { evidence (grade) }\end{array}$ \\
\hline Livraghi et $\mathrm{al}^{25}$ & 2008 & Italy & NRS & $118 / 100$ & $122 / 96$ & Low \\
\hline Wang et $\mathrm{al}^{26}$ & 2012 & People's Republic of China & NRS & $91 / 52$ & $98 / 41$ & Very low \\
\hline Pompili et $\mathrm{a}^{27}$ & 2013 & Italy & NRS & $109 / 99$ & NA & Very low \\
\hline Imai et $\mathrm{a}^{28}$ & 2013 & Japan & NRS & $51 / 38$ & NA & Very low \\
\hline Zhou et $\mathrm{a}^{29}$ & 2014 & People's Republic of China & NRS & $3|/ 2|$ & $35 / 17$ & Very low \\
\hline Liu et $\mathrm{al}^{30}$ & 2015 & People's Republic of China & NRS & $128 / 109$ & $162 / 75$ & Very low \\
\hline
\end{tabular}

Abbreviations: BCLC, Barcelona Clinic Liver Cancer; HCC, hepatocellular carcinoma; RFA, radiofrequency ablation; LR, liver resection; M, male; F, female; NRS, nonrandomized studies; NA, not applicable.

Five-year OS rate: Five studies ${ }^{25,26,28-30}$ reported this outcome. Patients in the radiofrequency ablation group had significantly lower 5 -year OS rate than those in the liver resection group $(\mathrm{RR}=0.84,95 \% \mathrm{CI}$ : $0.75-0.95, P=0.004$; heterogeneity: $I^{2}=50 \%, P=0.09$; Figure $2 \mathrm{~B}$ ).

Three-year DFS rate: Four studies ${ }^{26,27,29,30}$ reported this outcome. Patients in the radiofrequency ablation group had significantly lower 3-year DFS rate than those in the liver resection group ( $\mathrm{RR}=0.77,95 \% \mathrm{CI}: 0.60-0.98, P=0.04$; heterogeneity: $I^{2}=69 \%, P=0.02$; Figure $2 \mathrm{C}$ ).

Five-year DFS rate: Four studies ${ }^{26,28-30}$ reported this outcome. Patients in the radiofrequency ablation group had significantly lower 5-year DFS rate than those in the liver resection group ( $\mathrm{RR}=0.70,95 \% \mathrm{CI}$ : $0.52-0.94, P=0.02$; heterogeneity: $I^{2}=52 \%, P=0.10$; Figure 2D).

\section{Radiofrequency ablation versus liver resection for single BCLC early stage HCC}

The outcome measures data are presented in Table 4.

Three-year OS rate: Ten studies ${ }^{23,24,26-28,31-35}$ reported this outcome. Patients in the radiofrequency ablation group had significantly lower 3-year OS rate than those in the liver resection group ( $\mathrm{RR}=0.93,95 \% \mathrm{CI}$ : $0.88-0.98, P=0.003$; heterogeneity: $P^{2}=59 \%, P=0.008$; Figure $3 \mathrm{~A}$ ).

Five-year OS rate: Seven studies ${ }^{23,26,28,31-33,35}$ reported this outcome. Patients in the radiofrequency ablation group had significantly lower 5-year OS rate than those in the liver resection group ( $\mathrm{RR}=0.84,95 \% \mathrm{CI}: 0.75-0.94, P=0.002$; heterogeneity: $I^{2}=76 \%, P=0.0004$; Figure 3B).

Three-year DFS rate: Eight studies ${ }^{24,26-28,31,32,34,35}$ reported this outcome. Patients in the radiofrequency ablation group had significantly lower 3-year DFS rate than those in the liver resection group ( $\mathrm{RR}=0.72,95 \% \mathrm{CI}: 0.58-0.89, P=0.002$; heterogeneity: $I^{2}=83 \%, P<0.00001$; Figure $3 \mathrm{C}$ ).

Five-year DFS rate: Six studies ${ }^{26,28,31-33,35}$ reported this outcome. Patients in the radiofrequency ablation group had significantly lower 5-year DFS rate than those in the liver resection group ( $\mathrm{RR}=0.47,95 \% \mathrm{CI}$ : $0.33-0.67, P<0.0001$; heterogeneity: $I^{2}=77 \%, P=0.0005$; Figure 3D).

\section{Quality of evidence and publication bias}

Only one study had a moderate quality, ${ }^{23}$ and the quality of all other studies varied from low to very low (Tables 1 and 2). Thus, the current quality of evidence is considered very low.

Table 2 Characteristics and quality of included studies for single BCLC early stage HCC

\begin{tabular}{|c|c|c|c|c|c|c|c|}
\hline Author & Year & Country & Design & $\begin{array}{l}\text { Participants } \\
\text { (RFA/LR) }\end{array}$ & $\operatorname{Sex}(M / F)$ & Child-Pugh A/B & $\begin{array}{l}\text { Quality of the } \\
\text { evidence (grade) }\end{array}$ \\
\hline Hiraoka et $\mathrm{al}^{31}$ & 2008 & Japan & NRS & $105 / 59$ & $120 / 44$ & $|33 / 3|$ & Very low \\
\hline Huang et $\mathrm{a}^{23}$ & 2010 & $\begin{array}{l}\text { People's Republic } \\
\text { of China }\end{array}$ & $\mathrm{RCT}$ & $57 / 45$ & NA & NA & Moderate \\
\hline Wang et $\mathrm{a}^{26}$ & 2012 & $\begin{array}{l}\text { People's Republic } \\
\text { of China }\end{array}$ & NRS & $254 / 208$ & NA & $396 / 66$ & Very low \\
\hline Imai et $\mathrm{al}^{28}$ & 2013 & Japan & NRS & $82 / 101$ & $121 / 62$ & $167 / 26$ & Very low \\
\hline Wong et $\mathrm{al}^{32}$ & 2013 & $\begin{array}{l}\text { People's Republic } \\
\text { of China }\end{array}$ & NRS & $36 / 46$ & $48 / 34$ & $82 / 0$ & Very low \\
\hline Pompili et a ${ }^{27}$ & 2013 & Italy & NRS & $298 / 246$ & $375 / 169$ & $544 / 0$ & Low \\
\hline Yang et $\mathrm{al}^{33}$ & 2014 & Korea & NRS & $79 / 52$ & $97 / 34$ & $118 / 13$ & Low \\
\hline Fang et $\mathrm{al}^{24}$ & 2014 & $\begin{array}{l}\text { People's Republic } \\
\text { of China }\end{array}$ & $\mathrm{RCT}$ & $60 / 60$ & $88 / 32$ & $75 / 45$ & Low \\
\hline Kim et $\mathrm{al}^{34}$ & 2014 & Korea & NRS & $67 / 66$ & $100 / 33$ & $133 / 0$ & Very low \\
\hline Kang et $\mathrm{al}^{35}$ & 2015 & Korea & NRS & $438 / 142$ & $444 / 136$ & $502 / 78$ & Low \\
\hline
\end{tabular}

Abbreviations: BCLC, Barcelona Clinic Liver Cancer; HCC, hepatocellular carcinoma; RFA, radiofrequency ablation; LR, liver resection; M, male; F, female; NRS, nonrandomized studies; RCT, randomized controlled trial; NA, not applicable. 
Table 3 The long-term outcomes of radiofrequency ablation versus liver resection for single BCLC very early stage HCC

\begin{tabular}{|c|c|c|c|c|c|c|c|c|}
\hline \multirow[t]{3}{*}{ Studies } & \multicolumn{4}{|c|}{ Overall survival rates (\%) } & \multicolumn{4}{|c|}{ Disease-free survival rates (\%) } \\
\hline & \multicolumn{2}{|c|}{ 3-year } & \multicolumn{2}{|c|}{ 5-year } & \multicolumn{2}{|c|}{ 3-year } & \multicolumn{2}{|c|}{ 5-year } \\
\hline & RFA & LR & RFA & LR & RFA & LR & RFA & LR \\
\hline Livraghi et $\mathrm{al}^{25}$ & 75.0 & 89.0 & 47.0 & 68.0 & NA & NA & NA & NA \\
\hline Wang et $\mathrm{a}^{26}$ & 81.3 & 98.0 & 72.0 & 91.5 & 39.8 & 62.1 & 29.3 & 41.7 \\
\hline Pompili et $\mathrm{al}^{27}$ & 77.1 & 82.1 & NA & NA & 39.8 & 50.9 & NA & NA \\
\hline Imai et $\mathrm{al}^{28}$ & NA & NA & 74.0 & 90.5 & NA & NA & 30.5 & 46.9 \\
\hline Zhou et $\mathrm{a}^{29}$ & 90.3 & 85.7 & 80.6 & 81.0 & 83.9 & 81.0 & 71.0 & 76.2 \\
\hline Liu et $\mathrm{al}^{30}$ & 88.0 & 97.0 & 76.0 & 81.0 & 38.0 & 64.0 & 24.0 & 49.0 \\
\hline
\end{tabular}

Abbreviations: BCLC, Barcelona Clinic Liver Cancer; HCC, hepatocellular carcinoma; RFA, radiofrequency ablation; LR, Liver resection; NA, not applicable.

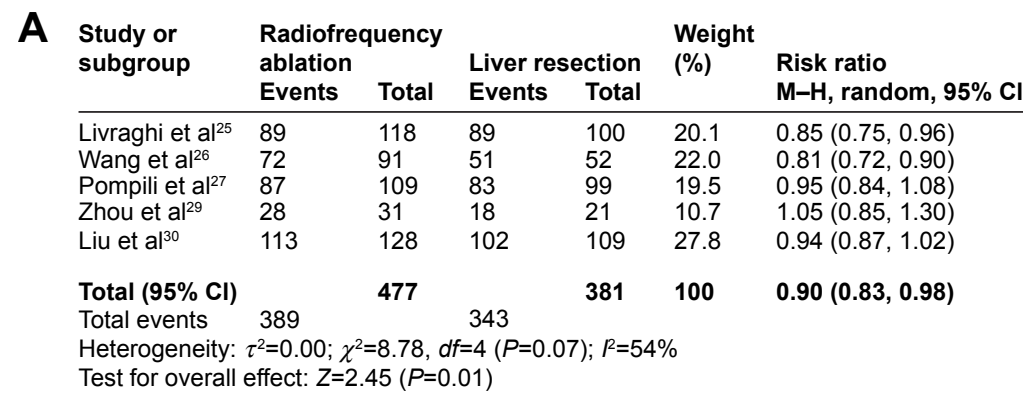

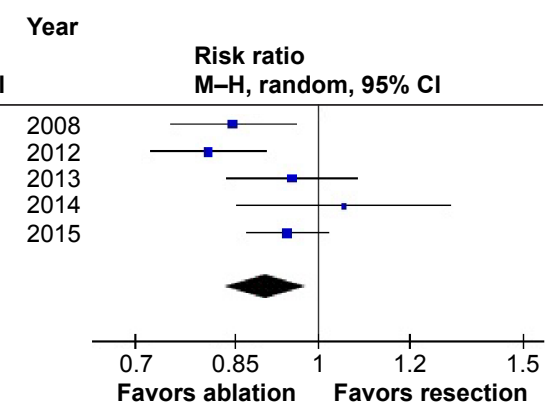

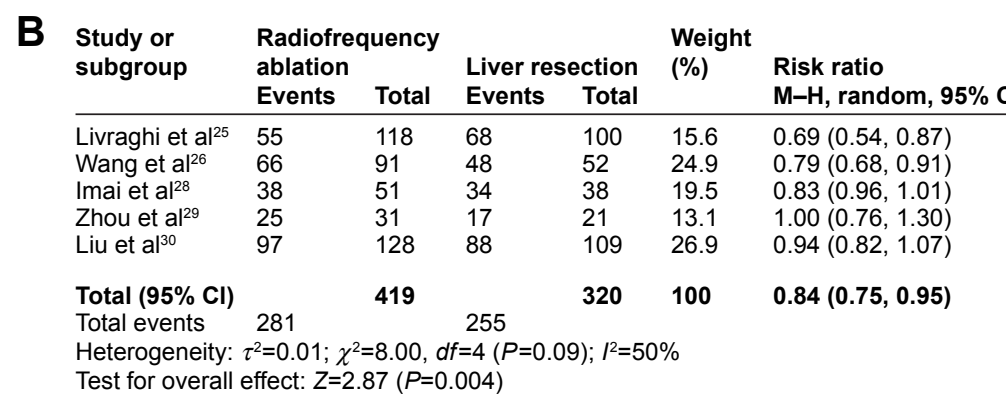

\begin{tabular}{|c|c|c|c|c|c|c|}
\hline \multirow[t]{2}{*}{$\begin{array}{l}\text { Study or } \\
\text { subgroup }\end{array}$} & \multicolumn{2}{|c|}{$\begin{array}{l}\text { Radiofrequency } \\
\text { ablation }\end{array}$} & \multicolumn{2}{|c|}{ Liver resection } & \multirow[t]{2}{*}{$\begin{array}{l}\text { Weight } \\
(\%)\end{array}$} & \multirow{2}{*}{$\begin{array}{l}\text { Risk ratio } \\
\text { M-H, random, } 95 \% \mathrm{C}\end{array}$} \\
\hline & Events & Total & Events & Total & & \\
\hline $\begin{array}{l}\text { Wang et } \mathrm{al}^{26} \\
\text { Pompili et } \mathrm{al}^{27} \\
\text { Zhou et } \mathrm{al}^{29} \\
\text { Liu et } \mathrm{al}^{30}\end{array}$ & $\begin{array}{l}36 \\
53 \\
26 \\
49\end{array}$ & $\begin{array}{l}91 \\
109 \\
31 \\
128\end{array}$ & $\begin{array}{l}32 \\
59 \\
17 \\
67\end{array}$ & $\begin{array}{l}52 \\
99 \\
21 \\
109\end{array}$ & $\begin{array}{l}21.9 \\
26.4 \\
26.0 \\
25.6\end{array}$ & $\begin{array}{l}0.64(0.46,0.90) \\
0.82(0.63,1.05) \\
1.04(0.80,1.34) \\
0.62(0.48,0.81)\end{array}$ \\
\hline $\begin{array}{l}\text { Total }(\mathbf{9 5 \%} \mathrm{CI}) \\
\text { Total events } \\
\text { Heterogeneity: } \\
\text { Test for overall }\end{array}$ & $\begin{array}{l}164 \\
\tau^{2}=0.04 ; \chi \\
\text { effect: } Z=2\end{array}$ & 359 & $\begin{aligned} & 175 \\
&= 3(P=0 . \\
&04)\end{aligned}$ & $\begin{array}{l}281 \\
2) ; l^{2}=(\end{array}$ & 100 & $0.77(0.60,0.98)$ \\
\hline
\end{tabular}

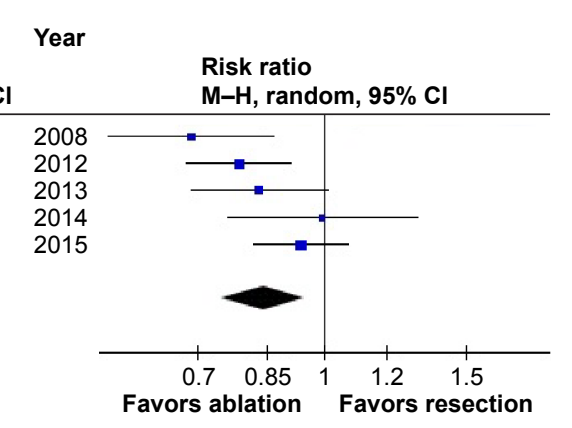

\begin{tabular}{|c|c|c|c|c|c|c|}
\hline \multirow[t]{2}{*}{$\begin{array}{l}\text { Study or } \\
\text { subgroup }\end{array}$} & \multicolumn{2}{|c|}{$\begin{array}{l}\text { Radiofrequency } \\
\text { ablation }\end{array}$} & \multicolumn{2}{|c|}{ Liver resection } & \multirow[t]{2}{*}{$\begin{array}{l}\text { Weight } \\
(\%)\end{array}$} & \multirow{2}{*}{$\begin{array}{l}\text { Risk ratio } \\
\mathrm{M}-\mathrm{H} \text {, random, } 95 \% \mathrm{C}\end{array}$} \\
\hline & Events & Total & Events & Total & & \\
\hline Wang et al ${ }^{26}$ & 27 & 91 & 21 & 52 & 22.5 & $0.73(0.47,1.16)$ \\
\hline Imai et al ${ }^{28}$ & 16 & 51 & 18 & 38 & 19.2 & $0.66(0.39,1.12)$ \\
\hline Zhou et al ${ }^{29}$ & 22 & 31 & 16 & 21 & 30.4 & $0.93(0.67,1.29)$ \\
\hline Liu et $\left.a\right|^{30}$ & 31 & 128 & 51 & 109 & 27.9 & $0.52(0.36,0.75)$ \\
\hline Total $(95 \% \mathrm{Cl})$ & & 301 & & 220 & 100 & $0.70(0.52,0.94)$ \\
\hline Total events & \multirow{3}{*}{\multicolumn{6}{|c|}{$\begin{array}{l}96 \quad 106 \\
\tau^{2}=0.05 ; \chi^{2}=6.25, d f=3(P=0.10) ; P^{2}=52 \% \\
\text { fffect: } Z=2.34(P=0.02)\end{array}$}} \\
\hline Heterogeneity: & & & & & & \\
\hline Test for overall & & & & & & \\
\hline
\end{tabular}

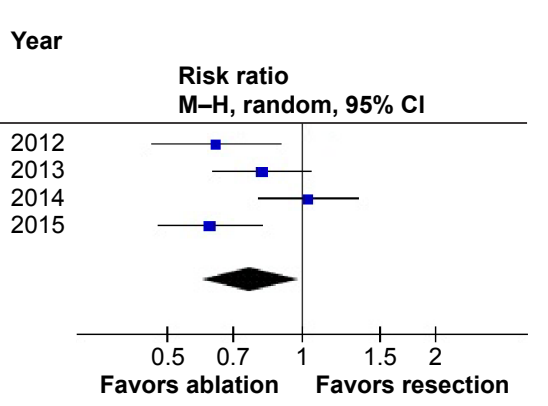


Table 4 The long-term outcomes of radiofrequency ablation versus liver resection for single BCLC early stage HCC

\begin{tabular}{|c|c|c|c|c|c|c|c|c|}
\hline \multirow[t]{3}{*}{ Studies } & \multicolumn{4}{|c|}{ Overall survival rates (\%) } & \multicolumn{4}{|c|}{ Disease-free survival rates (\%) } \\
\hline & \multicolumn{2}{|c|}{ 3-year } & \multicolumn{2}{|c|}{ 5-year } & \multicolumn{2}{|c|}{ 3-year } & \multicolumn{2}{|c|}{ 5-year } \\
\hline & RFA & LR & RFA & LR & RFA & LR & RFA & LR \\
\hline Hiraoka et $\mathrm{al}^{31}$ & 87.8 & 91.4 & 59.3 & 59.4 & 58.7 & 64.3 & 24.6 & 22.4 \\
\hline Huang et $\mathrm{a}^{23}$ & 77.2 & 95.6 & 61.4 & 82.2 & NA & NA & NA & NA \\
\hline Wang et $\mathrm{a}^{26}$ & 73.5 & 87.8 & 57.4 & 77.2 & 28.3 & 59.9 & 14.1 & 50.8 \\
\hline Imai et $\mathrm{al}^{28}$ & 84.6 & 92.5 & 59.4 & 87.5 & 36.3 & 58.7 & 23.9 & 46.8 \\
\hline Wong et $\mathrm{a}^{32}$ & 91.0 & 97.0 & 72.8 & 84.6 & 34.8 & 65.8 & 14.9 & 57.3 \\
\hline Pompili et a ${ }^{27}$ & 80.9 & 81.9 & NA & NA & 48.9 & 55.1 & NA & NA \\
\hline Yang et $\mathrm{al}^{33}$ & 90.9 & 96.0 & 86.6 & 93.6 & NA & NA & 26.8 & 54.4 \\
\hline Fang et $\mathrm{al}^{24}$ & 82.5 & 77.5 & NA & NA & 55.4 & 41.3 & NA & NA \\
\hline Kim et $\mathrm{al}^{34}$ & 74.4 & 92.3 & NA & NA & 39.6 & 60.0 & NA & NA \\
\hline Kang et $\mathrm{a}^{35}$ & 92.4 & 93.4 & 85.5 & 90.9 & 43.8 & 71.5 & 31.7 & 61.1 \\
\hline
\end{tabular}

Abbreviations: BCLC, Barcelona Clinic Liver Cancer; HCC, hepatocellular carcinoma; RFA, radiofrequency ablation; LR, liver resection; NA, not applicable.

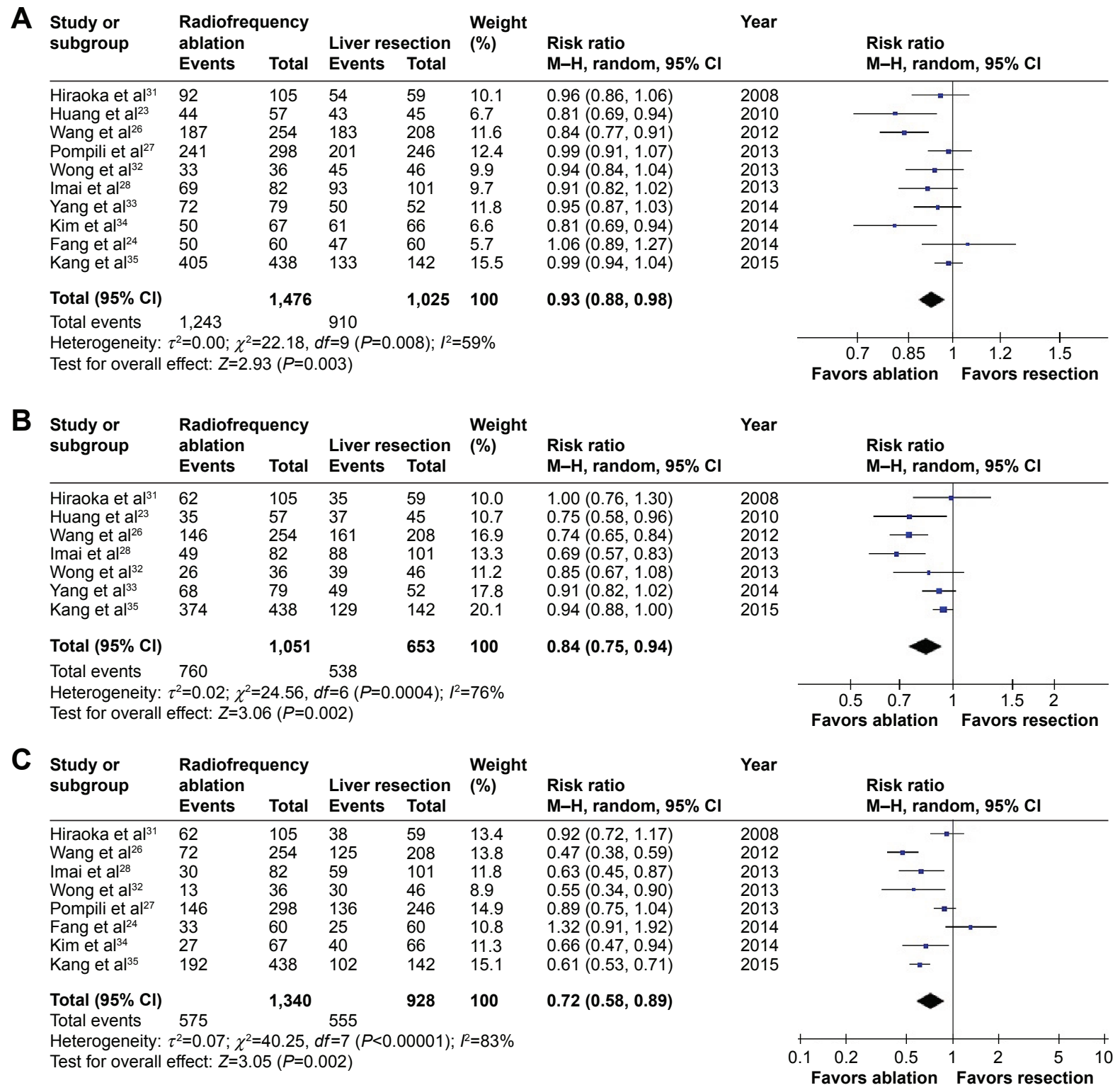

Figure 3 (Continued) 


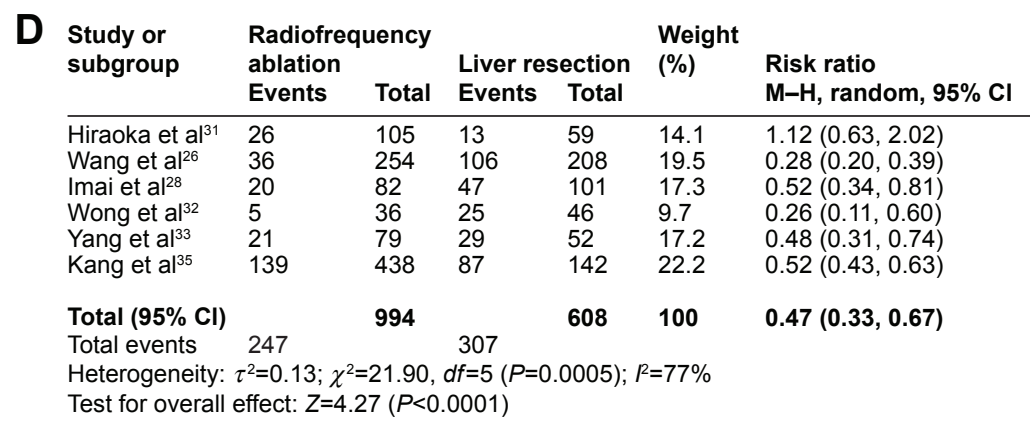

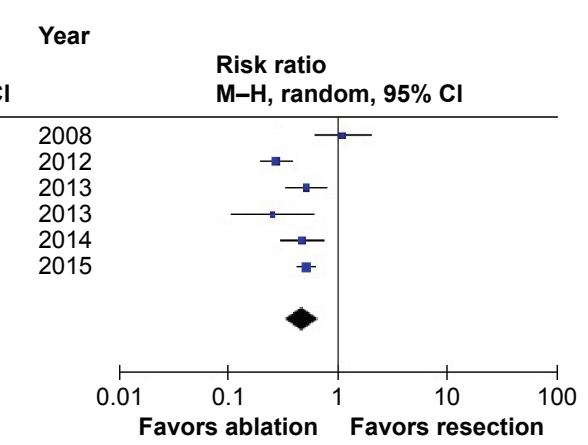

Figure 3 Forest plots of meta-analysis.

Notes: (A) Radiofrequency ablation versus liver resection for single BCLC early stage HCC in 3-year overall survival rates; (B) Radiofrequency ablation versus liver resection for single BCLC early stage HCC in 5-year overall survival rates; (C) Radiofrequency ablation versus liver resection for single BCLC early stage HCC in 3-year disease-free survival rates; (D) Radiofrequency ablation versus liver resection for single BCLC early stage HCC in 5-year disease-free survival rates.

Abbreviations: $\mathrm{Cl}$, confidence interval; M-H, Mantel-Haenszel test; MELD, model for end-stage liver disease; TNM, tumor node metastasis; CLIP, cancer of the liver Italian program; JIS, Japan integrated staging.

A funnel plot of the 3-year OS rate is presented in Figure 4. Neither visual asymmetry nor Egger's linear regression test $(P=0.15)$ of the funnel plot indicated publication bias.

\section{Discussion}

This systematic review comprehensively collected the available long-term survival outcomes for radiotherapy versus liver resection for single BCLC very early/early stage HCC. The results indicated that liver resection led to significantly better long-term survival outcomes than radiofrequency ablation in the management of single BCLC very early/ early stage HCC.

There are several HCC staging systems (eg, Child-Pugh, MELD, TNM, Okuda, CLIP, JIS, and BCLC), ${ }^{5-9}$ of which the BCLC staging system is the most commonly used..$^{15}$ The BCLC staging system is recommended by both the American Association for the Study of Liver Diseases (AASLD) and the European Association for the Study of the Liver (EASL). ${ }^{6,7}$

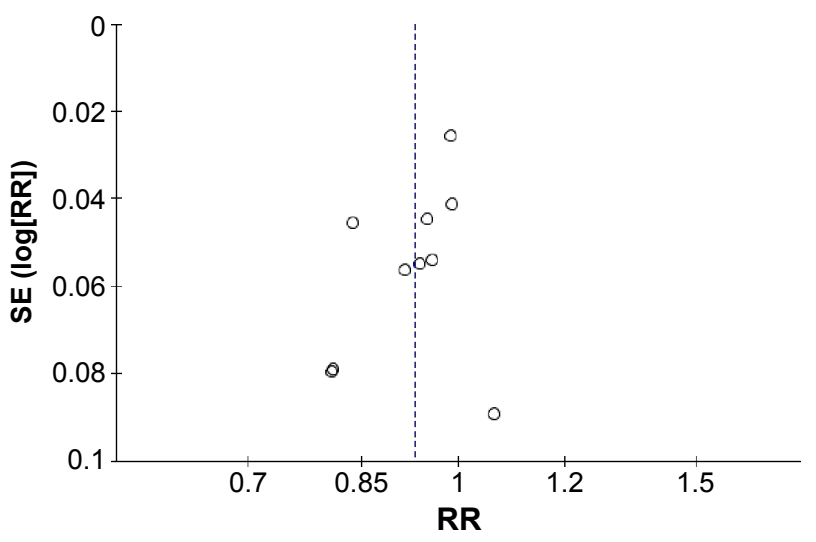

Figure 4 Funnel plot of the 3-year disease-free survival rate. Note: Dashed line represents the extension of the combined effect. Abbreviations: SE, standard error; RR, risk ratio.
According to the current AASLD and EASL guidelines, liver transplantation, liver resection, and radiofrequency ablation are the recommended treatment choices for single BCLC very early/early stage HCC. ${ }^{6,7}$ There is little evidence available on the optimal management of single BCLC very early/ early stage HCC. ${ }^{25-30}$ The AASLD and EASL guidelines are based on several retrospective cohort studies. ${ }^{6,7}$ The National Comprehensive Cancer Network and the Asian Pacific Association for the Study of the Liver do not mention the management of single BCLC very early stage HCC. ${ }^{8,9}$ Due to the shortcomings of liver transplantation, radiofrequency ablation and liver resection are commonly used to treat single BCLC very early/early stage HCC. ${ }^{24-35}$

Currently, the management of single BCLC very early/ early stage $\mathrm{HCC}$ is controversial. With a 5-year OS rate of $>50 \%$, liver resection is generally considered the preferred first-line treatment. ${ }^{6,7}$ Liver resection offers the possibility of the curative excision of the entire tumor and microscopic tumor thrombi. ${ }^{36}$ Alternatively, radiofrequency ablation is a minimally invasive technique that can be performed using a percutaneous or laparoscopic approach. ${ }^{37}$ Many systematic reviews have demonstrated comparable short-term survival outcomes, lower morbidity, and shorter hospitalization in the radiofrequency ablation group when compared to the liver resection group. ${ }^{16}$ However, the quality of published systematic reviews on this topic is poor due to the low quality of evidence and high clinical heterogeneity of the included studies. ${ }^{16}$

Compared to previous systematic reviews, the major advantages of this systematic review are the use of the BCLC staging system and the evaluation of long-term survival outcomes. The findings of this review suggest that liver resection results in significantly better survival outcomes than radiofrequency ablation in the management of single BCLC 
very early/early stage HCC. The improvement in survival outcomes over time after liver resection may be associated with an improved understanding of liver anatomy, improved perioperative care, and increased surgical experience. Furthermore, radiofrequency ablation has some disadvantages. Radiofrequency ablation causes thermal injury and is therefore not suitable for the treatment of HCC located close to other organs (eg, gallbladder, colon, or kidney). In addition, the heat-sink effect of radiofrequency ablation complicates the complete ablation of HCC adjacent to large vessels.

Our review is subject to the following limitations. First, only two RCTs with sample sizes were included in the metaanalysis; the other studies were all NRS. Second, much of the data in this review were from NRS, and the Jadad scores of those NRS were very low; therefore, the quality of evidence is considered very low. Third, most of the included studies were conducted in Eastern countries, and thus, the results of this review are only applicable to Eastern populations.

\section{Conclusion}

In summary, this review encompasses all currently available evidence regarding the comparison of radiofrequency ablation with liver resection for single BCLC very early/early stage HCC. Based on this evidence, liver resection appears to be superior to radiofrequency ablation in terms of long-term survival outcomes. Future high-quality RCTs from Western countries are necessary to confirm our findings.

\section{Acknowledgments}

We would like to thank Jian $\mathrm{Hu}$ and Yao Cheng, who assisted with the development of the review.

\section{Author contributions}

He Z-X and Zhang $\mathrm{W}$ designed the study. Xiang $\mathrm{P}$ and Gong J-P performed the literature research and collected the data. Cheng N-S analyzed the data. He Z-X and Zhang W wrote the paper. All authors contributed toward data analysis, drafting and critically revising the paper and agree to be accountable for all aspects of the work.

\section{Disclosure}

The authors report no conflicts of interest in this work.

\section{References}

1. Ferlay J, Shin HR, Bray F, Forman D, Mathers C, Parkin DM. Estimates of worldwide burden of cancer in 2008: GLOBOCAN 2008. Int J Cancer. 2010;127(12):2893-2917.

2. Forner A, Llovet JM, Bruix J. Hepatocellular carcinoma. Lancet. 2012; 379(9822):1245-1255.
3. de Lope CR, Tremosini S, Forner A, Reig M, Bruix J. Management of HCC. J Hepatol. 2012;56(suppl 1):S75-S87.

4. El-Serag HB. Hepatocellular carcinoma. N Engl J Med. 2011;365(12): 1118-1127.

5. Bruix J, Sherman M; Practice Guidelines Committee, American Association for the Study of Liver Diseases. Management of hepatocellular carcinoma. Hepatology. 2005;42(5):1208-1236.

6. Bruix J, Sherman M; American Association for the Study of Liver Diseases. Management of hepatocellular carcinoma: an update. Hepatology. 2011;53(3):1020-1022.

7. European Association for the Study of the Liver; European Organisation for Research and Treatment of Cancer. EASL-EORTC clinical practice guidelines: management of hepatocellular carcinoma. $J$ Hepatol. 2012;56(4):908-943.

8. Omata M, Lesmana LA, Tateishi R, et al. Asian Pacific Association for the Study of the Liver consensus recommendations on hepatocellular carcinoma. Hepatol Int. 2010;4(2):439-474.

9. National Comprehensive Cancer Network [webpage on the Internet]. NCCN Clinical Practice Guidelines in Oncology: Hepatobiliary Cancers. Version 2 [updated March 2015]. The NCCN Guideline. Available from: http://www.nccn.org/professionals/physician_gls/pdf/ hepatobiliary.pdf. Accessed January 12, 2016.

10. Chen MS, Li JQ, Zheng Y, et al. A prospective randomized trial comparing percutaneous local ablative therapy and partial hepatectomy for small hepatocellular carcinoma. Ann Surg. 2006;243(3):321-328.

11. Feng K, Yan J, Li X, et al. A randomized controlled trial of radiofrequency ablation and surgical resection in the treatment of small hepatocellular carcinoma. J Hepatol. 2012;57(4):794-802.

12. Sato M, Watanabe Y, Ueda S, et al. Microwave coagulation therapy for hepatocellular carcinoma. Gastroenterology. 1996;110(5): $1507-1514$.

13. Seki T, Nonaka T, Kubota Y, Mizuno T, Sameshima Y. Ultrasonically guided percutaneous ethanol injection therapy for hepatocellular carcinoma. Am J Gastroenterol. 1989;84(11):1400-1407.

14. Ng KK, Poon RT, Chan SC, et al. High-intensity focused ultrasound for hepatocellular carcinoma: a single-center experience. Ann Surg. 2011; 253(5):981-987.

15. Llovet JM, Brú C, Bruix J. Prognosis of hepatocellular carcinoma: the BCLC staging classification. Semin Liver Dis. 1999;19(3):329-338.

16. Wang Y, Luo Q, Li Y, Deng S, Li X, Wei S. A systematic assessment of the quality of systematic reviews/meta-analyses in radiofrequency ablation versus hepatic resection for small hepatocellular carcinoma. $J$ Evid Based Med. 2014;7(2):103-120.

17. Guyatt GH, Oxman AD, Schünemann HJ, Tugwell P, Knottnerus A. GRADE guidelines: a new series of articles in the Journal of Clinical Epidemiology. J Clin Epidemiol. 2011;64(4):380-382.

18. Sterne JAC, Egger M, Moher D, editors [homepage on the Internet]. Chapter 10: addressing reporting biases. In: Higgins JPT, Green S, editors. Cochrane Handbook for Systematic Reviews of Interventions. Version 5.1.0 [updated March 2011]. The Cochrane Collaboration. Available from: www.cochrane-handbook.org. Accessed January 12, 2016.

19. Egger M, Davey Smith G, Schneider M, Minder C. Bias in meta-analysis detected by a simple, graphical test. BMJ. 1997;315(7109):629-634.

20. Deeks JJ, Higgins JPT, Altman DG, editors [homepage on the Internet]. Chapter 9: analysing data and undertaking meta-analyses. In: Higgins JPT, Green S, editors. Cochrane Handbook for Systematic Reviews of Interventions Version 5.1.0 [updated March 2011]. The Cochrane Collaboration. Available from: www.cochrane-handbook.org. Accessed January 12, 2016.

21. Higgins JPT, Green S, editors [homepage on the Internet]. Cochrane Handbook for Systematic Reviews of Interventions Version 5.1.0 [updated March 2011]. The Cochrane Collaboration. Available from: www.cochrane-handbook.org. Accessed January 12, 2016.

22. Shamseer L, Moher D, Clarke M, et al. Preferred reporting items for systematic review and meta-analysis protocols (PRISMA-P) 2015: elaboration and explanation. BMJ. 2015;349:g7647. 
23. Huang J, Yan L, Cheng Z, et al. A randomized trial comparing radiofrequency ablation and surgical resection for $\mathrm{HCC}$ conforming to the Milan criteria. Ann Surg. 2010;252(6):903-912.

24. Fang Y, Chen W, Liang X, et al. Comparison of long-term effectiveness and complications of radiofrequency ablation with hepatectomy for small hepatocellular carcinoma. J Gastroenterol Hepatol. 2014; 29(1):193-200.

25. Livraghi T, Meloni F, Di Stasi M, et al. Sustained complete response and complications rates after radiofrequency ablation of very early hepatocellular carcinoma in cirrhosis: is resection still the treatment of choice? Hepatology. 2008;47(1):82-89.

26. Wang JH, Wang CC, Hung CH, Chen CL, Lu SN. Survival comparison between surgical resection and radiofrequency ablation for patients in BCLC very early/early stage hepatocellular carcinoma. J Hepatol. 2012; 56(2):412-418.

27. Pompili M, Saviano A, de Matthaeis N, et al. Long-term effectiveness of resection and radiofrequency ablation for single hepatocellular carcinoma $\leq 3 \mathrm{~cm}$. Results of a multicenter Italian survey. J Hepatol. 2013;59(1):89-97.

28. Imai K, Beppu T, Chikamoto A, et al. Comparison between hepatic resection and radiofrequency ablation as first-line treatment for solitary small-sized hepatocellular carcinoma of $3 \mathrm{~cm}$ or less. Hepatol Res. 2013; 43(8):853-864.

29. Zhou Z, Lei J, Li B, et al. Liver resection and radiofrequency ablation of very early hepatocellular carcinoma cases (single nodule $<2 \mathrm{~cm}$ ): a single-center study. Eur J Gastroenterol Hepatol. 2014;26(3): 339-344.
30. Liu PH, Hsu CY, Hsia CY, et al. Surgical resection versus radiofrequency ablation for single hepatocellular carcinoma $\leq 2 \mathrm{~cm}$ in a propensity score model. Ann Surg. Epub 2015 Mar 13.

31. Hiraoka A, Horiike N, Yamashita Y, et al. Efficacy of radiofrequency ablation therapy compared to surgical resection in 164 patients in Japan with single hepatocellular carcinoma smaller than $3 \mathrm{~cm}$, along with report of complications. Hepatogastroenterology. 2008;55(88):2171-2174.

32. Wong KM, Yeh ML, Chuang SC, et al. Survival comparison between surgical resection and percutaneous radiofrequency ablation for patients in Barcelona Clinic Liver Cancer early stage hepatocellular carcinoma. Indian J Gastroenterol. 2013;32(4):253-257.

33. Yang HJ, Lee JH, Lee DH, et al. Small single-nodule hepatocellular carcinoma: comparison of transarterial chemoembolization, radiofrequency ablation, and hepatic resection by using inverse probability weighting. Radiology. 2014;271(3):909-918.

34. Kim JM, Kang TW, Kwon CH, et al. Single hepatocellular carcinoma $\leq 3 \mathrm{~cm}$ in left lateral segment: liver resection or radiofrequency ablation? World J Gastroenterol. 2014;20(14):4059-4065.

35. Kang TW, Kim JM, Rhim H, et al. Small Hepatocellular carcinoma: radiofrequency ablation versus nonanatomic resection-propensity score analyses of long-term outcomes. Radiology. 2015;275(3):908-919.

36. Vivarelli M, Guglielmi A, Ruzzenente A, et al. Surgical resection versus percutaneous radiofrequency ablation in the treatment of hepatocellular carcinoma on cirrhotic liver. Ann Surg. 2004;240(1):102-107.

37. Machi J, Uchida S, Sumida K, et al. Ultrasound-guided radiofrequency thermal ablation of liver tumors: percutaneous, laparoscopic, and open surgical approaches. J Gastrointest Surg. 2001;5(5):477-489.
Therapeutics and Clinical Risk Management

\section{Publish your work in this journal}

Therapeutics and Clinical Risk Management is an international, peerreviewed journal of clinical therapeutics and risk management, focusing on concise rapid reporting of clinical studies in all therapeutic areas, outcomes, safety, and programs for the effective, safe, and sustained use of medicines. This journal is indexed on PubMed Central, CAS,

\section{Dovepress}

EMBase, Scopus and the Elsevier Bibliographic databases. The manuscript management system is completely online and includes a very quick and fair peer-review system, which is all easy to use. Visit http://www.dovepress.com/testimonials.php to read real quotes from published authors.

Submit your manuscript here: http://www.dovepress.com/therapeutics-and-clinical-risk-management-journal 